\title{
A Rare Case of Hand Angioleiomyoma
}

\author{
Miry A*, Tiabi E, Aissaoui A, Mouhoub M, Karich N and Bennani A \\ Pathology department, Mohamed VI university hospital, Morocco
}

\begin{abstract}
Angioleiomyoma is a benign neoplasm, occurring commonly in the lower limbs and exceptionally in the hand. This tumor is made of two components: smooth muscles and blood vessels. We report a case of angioleiomyoma of the hand in a 54 years-old female patient, who presented with a $3 \mathrm{~cm}$ swelling on the dorsal aspect of her right hand. An excision of the nodule was performed. Histological and immunohistochemical features were compatible with the diagnosis of a benign Angioleiomyoma. Pain, found in 50\% of cases, is the most frequent symptom. However, no specific features are presented by this tumor, explaining why it is rarely diagnosed pre-operatively. Since this lesion has no specific radiological characteristics too, pathological examination makes its diagnosis.
\end{abstract}

KEYWORDS: Angioleiomyoma; Hand; Angiomyoma

\section{INTRODUCTION}

Angioleiomyoma, also called vascular leiomyoma, dermal angioma or angiomyoma, is a rare benign tumor that is made of two components: smooth muscle and blood vessels [1]. This tumor is classified according to the WHO as a pericytic benign tumour [2]. It can be found throughout the body although the most typical presentation of this tumor is in lower limbs in middle-aged women [3]. It manifests in form of a slow-growing firm mass. It has no specific clinico-radiological characteristics and is therefore rarely diagnosed pre-operatively [3]. Angioleiomyoma has been rarely reported in the hand with only very few case reports [4].

\section{CASE REPORT}

We report the case of a 54-years-old right hand dominant female patient. She has no comorbidities. She presented with a nodule on the dorsum of the right hand, gradually evolving during a period of 7 years. The patient had mild pain. Clinical examination showed an ovoid, firm, $3 \times 2 \mathrm{~cm}$ swelling over the dorsum of the right hand with no other similar lesions elsewhere. The edges of the nodule were well defined. The physician prescribed no Radiographic or ultrasounds examination. An excision biopsy was performed grossly, the nodule was well circumscribed and encapsulated. The color was grey-white, and it was measuring about $3 \mathrm{~cm} \times 2 \mathrm{~cm}$.

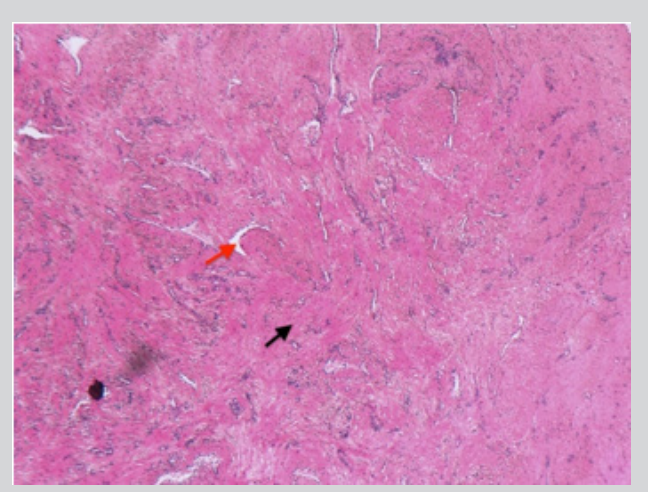

Figure 1: Microphotography showing that the tumor is made of two components: smooth muscle (Black arrow) and blood vessels (Red arrow) (HE; 40X).
Quick Response Code:

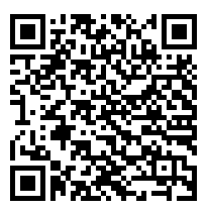

Address for correspondence: Miry A, Pathology department, Mohamed VI university hospital, Morocco

Received: January 28, 2020

Published: February 18, 2020

How to cite this article: Miry A, Tiabi E, Aissaoui A, Mouhoub M, Karich N and Bennani A . A Rare Case of Hand Angioleiomyoma. 2020 - 2(1) OAJBS.ID.000142.

DOI: $10.38125 / \mathrm{OAJBS} .000142$ 
Histopathological examination revealed a tumor composed of spindle cells arranged haphazardly, interspersed with thick-walled and thin-walled blood vessels. The cells showed vesicular cigarshaped/fusiform nuclei and were seen to merge with the outer smooth muscle layer of blood vessels (Figure $1 \& 2$ ).

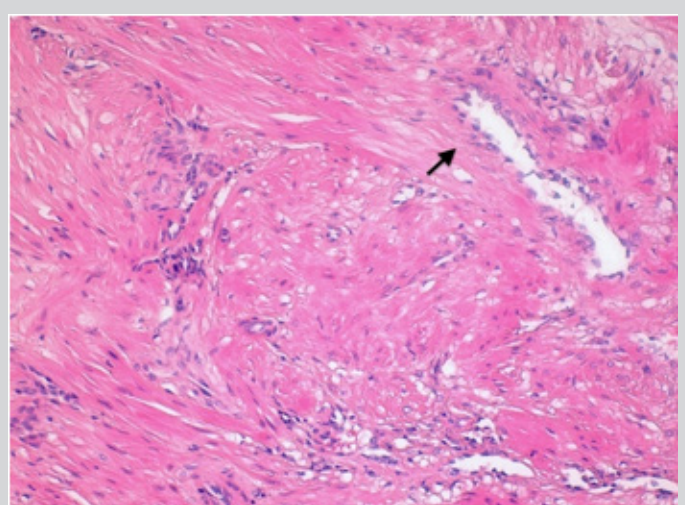

Figure 2: Microphotography at higher magnification, showing the cigar-shaped nuclei of smooth muscle cells and the emergence of the muscular component from the outer layer of blood vessels (Arrow) (HE; 200X).

CD34 was expressed by blood vessels. SMA was expressed by smooth muscle cells. Anti-S100 protein identified no associated nerves in the lesion (Figure 3-5). No evidence of recurrence was noted after a follow-up of 3 years.

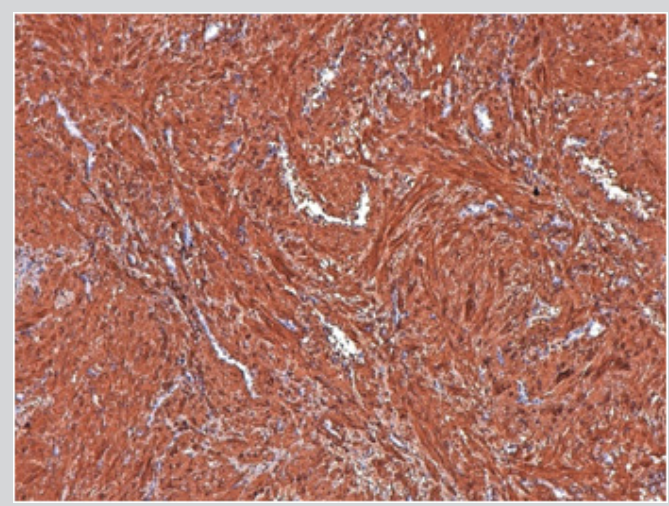

Figure 3: SMA was expressed by smooth muscle cells.

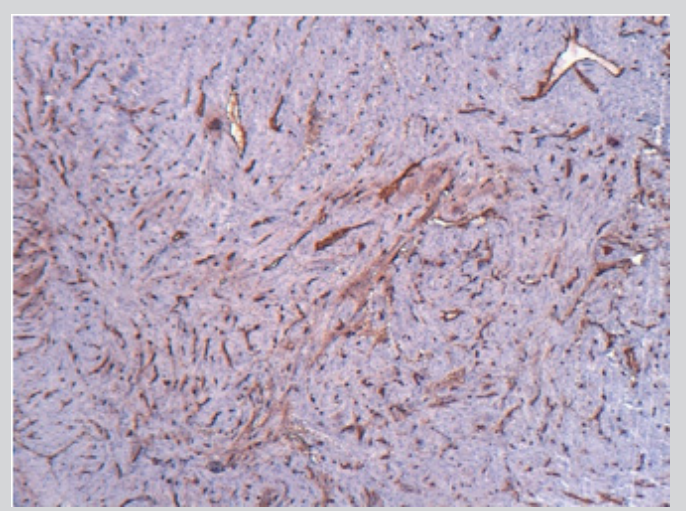

Figure 4: CD34 shows the importance of the vascular component in the tumor.

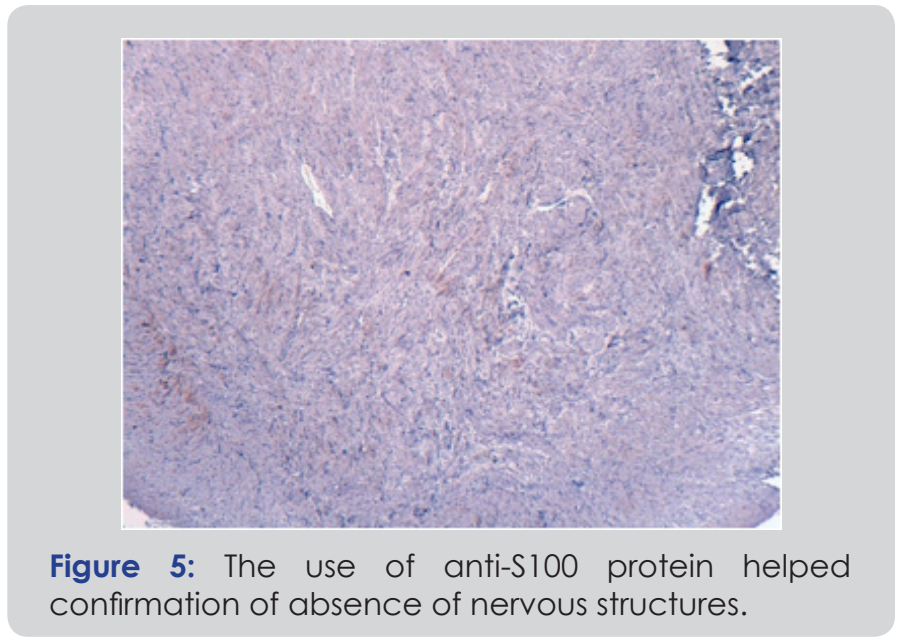

\section{DISCUSSION}

Angioleiomyoma occurs exceptionally in the upper limb, with an incidence of less than $1 \%$ of all soft tissue tumors on this location [5]. It is seldom diagnosed pre-operatively [3]. In a study about 437 hand tumors, Butler has found only one case of leiomyoma [6]. The most affected age group is between third to sixth decades [7]. Females are more frequently affected with a sex ratio of 1:1.7, although in some large series, no sex predilection was observed [3,7]. Moreover, Hachisuga et al have noted that upper limb angioleiomyomas occurred more commonly in male than female patients [8]. The most common location is the appendicular skeleton (89\%), especially the lower limbs (75\%) [7]. A paroxysmal, mechanical pain is the appealing symptom in $50 \%$ of cases although painful upper limb angioleiomyomas are less frequent compared with those located in the lower limb. This pain is classically precipitated by light touch and changes in temperature [8]. The pathogenesis and etiology of this tumor is not yet entirely elucidated [5]. However, some theories have been proposed as causative factors, such us repetitive micro trauma, venous stasis and estrogen imbalance [9]. Moreover, these lesions have been observed as smooth muscle proliferation in a background of hamartoma or haemangioma $[7,9,10]$. Angioleiomyoma appears as a well-defined homogenous image when examined through ultrasound imaging. [1] MRI shows a slightly hyperintense image mass, compared with skeletal muscle in T1-weighed images. In T2weighed images, the lesion appears as hyperintense and isointense regions when compared with skeletal muscles [11].

The peripheral fibrous capsule appears in form of a T2weighted hypointense signal.

At the histological level, these tumors can be classified into three types [12]

a) A solid type, representing the most frequent type (66\%), occurs commonly in women, often painful and is made of abundant compact smooth muscle cells containing few slit-like vascular channels.

b) A venous type (23\%), occurring commonly in men, usually painless and is made of vascular channels walled by Smooth muscle.

c) A cavernous type (11\%), occurring commonly in men, and is presented at the histological level in form of abundant dilated vascular channels with very fewer smooth muscles.

Other inconstant findings include possible calcifications, hyalinisation, myxoid degeneration, hemorrhage and normal nerve 
fibers or adipose tissue [7,9]. An association was found between hyalinisation/myxoid degeneration and the presence of a history of pain $[8,13]$.

In one series, about 14 cases of hand angioleiomyoma, the presence of an organizing thrombus in one case was correlated with a history of sudden increase in size of the lesion associated with a rapid onset of pain [3]. Nerve fibers are frequently found in and around the capsule and occasionally within the lesion [3]. The presence of adipose tissue within the lesion could be in favor of an hamartomatous nature of the lesion [3]. The pain described by patients could be in part explained by ischemia secondary to vessels constriction due to nerves activity when they exist in the lesion [9]. Nevertheless, in our case no nervous tissue was found even if the patient reported chronic mild pain. At the Immunohistological level, the smooth muscular component is highlighted by smooth muscle actin (SMA) whereas the vascular component can be demonstrated by vascular markers (CD31 and CD34). Although the majority of cases had a benign behavior, very few cases of vascular leiomyosarcoma have been reported. The standard treatment is excision, with a low risk of recurrence when excision is complete.

\section{CONCLUSION}

Angioleiomyoma is a benign neoplasm, occurring commonly in the lower limbs and exceptionally in the hand. Pain, found in $50 \%$ of cases, is the most frequent symptom. Since this lesion has no specific clinical or radiological characteristics, pathological examination makes its diagnosis.

\section{REFERENCES}

1. Ramesh P, Annapureddy SR, Khan F (2004) Angioleiomyoma: a clinical, pathological and radiological review. Int J Clin Pract 58(6): 587-591.
2. Hisaoka M (2013) Angioleiomyoma. In: Fletcher CDM, Bridge JA, Hogendoorn PCW $4^{\text {th }}$ (edn.). World health organization classification of tumors of soft tissue and bone. Lyon: IARC Press. France, Pp. 120-121.

3. Lawson GM, Salter DM, Hooper G (1995) Angioleiomyomas of the hand: a report of 14 cases. J Hand Surg Br 20(4): 479-483.

4. Houdek MT, Rose PS, Shon W (2013) Angioleiomyoma of the upper extremity. J Hand Surg Am 38(8): 1579-1583.

5. Butler ED, Hamill JP, Seipel RS, de Lorimier AA (1960) Tumours of the hand: A ten-year survey and report of 437 cases. Am J Surg 100(2): 293302.

6. Hachisuga T, Hashimoto H, Enjoji M (1984) Angioleiomyoma: A clinicopathologic reappraisal of 562 cases. Cancer 54(1): 126-130.

7. Dey B, Bharti JN, Gautam P (2014) Angioleiomyoma of the forearm. J Lab Physicians 6(1): 53-54.

8. Duhig JT, Ayer JP (1959) Vascular leiomyoma. A study of sixtyone cases. Arch Pathol 68: 424-430.

9. Hwang JW, Ahn JM, Kang HS (1998) Vascular leiomyoma of an extremity: MR imaging-pathology correlation. AJR Am J Roentgenol 171(4): 981985.

10. Morimoto S (1973) Angiomyoma. A clinicopathologic study. Med J Kagoshima Univ 24: 663-683.

11. Agarwal S, Gupta SK, Tejwani N (2009) Angioleiomyoma of broad ligament. J Gynecol Endosc Surg 1(2): 116-117.

12. Herren DB, Zimmermann A, Büchler U (1995) Vascular leiomyoma in an index finger undergoing malignant transformation. J Hand Surg Br 20(4): 484-487.

13. Neviaser RJ, Newman W (1977) Dermal angiomyoma of the upper extremity. J Hand Surg Am 2(4): 271-274. 